\title{
DESAIN ULANG TPST SAMPURNO SIDOARJO MENJADI TPS3R
}

\author{
Muhammad Naufal Rozan ${ }^{1}$, Widya Nilandita², Arqowi Pribadi ${ }^{3}$, Amrullah $^{4}$, Shinfi Wazna \\ Auvaria $^{5}$ \\ 1,2,3,4,5 Universitas Islam Negeri Sunan Ampel, Surabaya, Indonesia \\ Email: ${ }^{1}$ mnaufal726@gmail.com, ${ }^{2}$ widyanilandita@gmail.com, ${ }^{3}$ arqowi.pribadi@uinsby.com
}

Masuk: 16 Januari 2021, Revisi masuk: 21 Februari 2021, Diterima: 3 Agustus 2021

\begin{abstract}
Waste processing at the Sampurno TPST is still carried out by sorting the waste to the final processing site. Therefore, it is necessary to redesign the planning of TPST Sampurno to become MRF so that it can run optimally. The research aimed to determine the condition of existing waste management, to identify the pile of waste, density and composition, to compare the feasibility of TPST with Permen PU No.03 of 2013, to redesign TPST and to calculate the budget required. This study used qualitative methods in the form of secondary data and also quantitative methods in the form of sampling according to the SNI 19-3964-1994. The results of the observations showed that the existing waste management conditions were only transported from the source to TPST then transported to TPA and the pile of waste was $24.14 \mathrm{m3}$, of waste density of $162.12 \mathrm{~kg} / \mathrm{m3}$, the pile of waste was $0.41 \mathrm{~kg} /$ person / day which was dominated by organic waste. It can be concluded that TPST Sampurno is not in accordance with Permen PU No. 03/2013. It needs to be redesigned to become TPS3R in order to function optimally in managing waste in Kalisampurno Village with the budget Rp. 2,021,010,000.00.
\end{abstract}

Keywords: MRF, TPST, Waste.

INTISARI

Pengolahan sampah di TPST Sampurno masih dilakukan dengan angkut-pemilahan-buang ke Tempat Pemrosesan Akhir. Maka dari itu perlu dilakukannya Redesain perencanaan TPST Sampurno menjadi Tempat Pengolahan Sampah Reduce, Reuse, Recycle (TPS3R) agar berjalan secara optimal. Penelitian bertujuan untuk mengetahui kondisi pengelolaan eksisting sampah, identifikasi timbulan, densitas dan komposisi sampah, membandingkan kelayakan TPST dengan Permen PU No.03 Tahun 2013, melakukan redesain TPST serta menghitung RAB yang diperlukan. Dalam penelitian ini menggunakan metode kualitatif berupa data sekunder dan juga metode kuantitatif berupa pengambilan sampel sesuai dengan SNI 19-3964-1994. Hasil observasi menunjukkan kondisi pengelolaan eksisting sampah hanya diangkut dari sumber ke TPST kemudian diangkut menuju TPA dan timbulan sampah sebesar 24,14 m3 densitas sampah sebesar $162,12 \mathrm{~kg} / \mathrm{m} 3$ timbulan sampah sebesar 0,41 $\mathrm{kg} / \mathrm{jiwa} / \mathrm{hari}$ dimana komposisi sampah didominasi oleh sampah organik. TPST Sampurno tidak sesuai dengan PERMEN PU No.03 Tahun 2013 dan TPST Sampurno perlu redesain menjadi TPS3R agar berfungsi dengan optimal dalam mengelola sampah di Kelurahan Kalisampurno dengan RAB sebesar Rp. 2.021.010.000,00.

Kata-kata kunci: Sampah, TPST, TPS3R.

\section{PENDAHULUAN}

Sampah merupakan hasil pembuangan dari manusia yang sudah tidak digunakan kembali. Seiring berjalannya waktu sampah tersebut akan semakin menumpuk apabila tidak diolah dan dikelola dampaknya pun akan mengakibatkan gangguan kesehatan serta lingkungan. Jumlah produksi sampah tiap tahun meningkat dan melebihi kapasitas daya tampung yang tersedia (Raharjo, 2015). Keterbatasan daya tampung tempat pengolahan sampah perlu dilakukan desain ulang perencanaan TPST menjadi TPS3R
(Pratama dkk., 2017). Penelitian ini diharapkan bisa memberikan masukan untuk pertimbangan kebijakan pemerintah dalam mengatasi persampahan di Sidoarjo. Tujuan penelitian ini adalah mengetahui kondisi di lapangan pada TPST Sampurno.

\section{METODE PENELITIAN}

Data penelitian terdiri atas dua jenis, yaitu data sekunder dan data primer. 


\section{Pengumpulan data sekunder}

Data sekunder didapatkan dari dokumen penunjang pada dinas terkait, yaitu Badan Pusat Statistik Kabupaten Sidoarjo. Data sekunder yang dalam penelitian ini berupa:
a. Peta administrasi
Kelurahan Kalisampurno.
b. Data kependudukan.

\section{Pengumpulan data primer}

Data primer diperoleh dari hasil observasi untuk mendapatkan gambaran kondisi eksisting TPST Sampurno terkait timbulan, densitas, dan komposisi sampah. Pengambilan sampel berdasarkan dengan SNI 19-3964-1994 tentang Metode Pengambilan dan Pengukuran Contoh Timbulan Sampah Perkotaan. Metode yang digunakan adalah sebagai berikut:
a. Tempat observasi adalah di TPST Sampurno.
b. Pengambilan sampel selama 8 hari .
c. Sampel sampah yang diambil sebesar $100 \mathrm{~kg}$.
d. Pengambilan sampel dilakukan menggunakan alat bantu dan perlengkapan keselamatan.
Pengukuran sampel timbulan dan densitas sampah adalah sebagai berikut:

a. Sampel sampah diambil pada beberapa titik.

b. Sampel diletakkan ke kotak sampah.

c. Sampah ditimbang dan dicatat beratnya.

d. Sampah dihentakkan sebanyak 3 kali.

e. Penurunan sampah diukur dan dicatat volumenya.

f. Dihitung densitas sampah dengan rumus (1):

$$
\begin{aligned}
& \rho=\frac{m}{V s} \\
& \text { dimana: } \\
& \rho=\text { densitas sampah }(\mathrm{Kg} / \mathrm{m} 3) \\
& \mathrm{m}=\text { berat sampah }(\mathrm{Kg}) \\
& \text { Vs }=\text { Volume sampah }(\mathrm{m} 3)
\end{aligned}
$$

Cara pengukuran sampel komposisi sampah hampir sama dengan timbulan dan densitas, tetapi dipilah menurut komponen masing-masing sampah. Komposisi sampah dihitung dengan rumus (2), yaitu:

$$
\begin{aligned}
& \mathrm{n}= \frac{a}{b} \times 100 \% \\
& \text { dimana: } \\
& \mathrm{n}=\text { persentase komposisi sampah }(\%) \\
& \mathrm{a}=\text { berat masing-masing komposisi } \\
& \text { sampah }(\mathrm{kg}) \\
& \mathrm{b}=\text { berat total komposisi sampah yang } \\
& \quad \text { diambil }(\mathrm{kg}) .
\end{aligned}
$$

Load Count Analysis adalah salah satu metode yang digunakan untuk menghitung timbulan sampah. Rumus Load count analysis adalah:

Timbulan sampah = Jumlah sampah gerobak $\mathrm{x}$ densitas sampah

\section{PEMBAHASAN \\ Kondisi Eksisting Pengelolaan Sampah}

Kondisi persampahan di Kelurahan Kalisampurno dilihat dari beberapa aspek teknis operasional meliputi pewadahan, pengumpulan, pemindahan (TPST) dan pengangkutan. Sebagian besar masyarakat melakukan pewadahan sampah dalam satu wadah individual di masing-masing sumber sampah. Berdasarkan tempat sumber sampah, pewadahan yang dilakukan oleh masyarakat Kelurahan Kalisampurno adalah sebagai berikut:

a. Rumah tangga

Sumber sampah dihasilkan dari kegiatan rumah tangga. Pewadahan yang digunakan tergolong wadah permanen dan semi permanen.

b. Kantor

Sumber sampah dihasilkan dari kegiatan perkantoran. Pewadahan yang digunakan tergolong wadah permanen dan semi permanen.

c. Pasar

Sumber sampah dihasilkan dari kegiatan jual beli. Pewadahan yang digunakan tergolong wadah permanen dan semi permanen.

d. Tempat pendidikan/sekolah

Sumber sampah dihasilkan dari kegiatan pendidikan. Pewadahan yang digunakan tergolong wadah permanen dan semi permanen, dan tempat sampah dibedakan menjadi 2, yaitu wadah organik dan wadah non-organik.

e. Home Industry

Sumber sampah dihasilkan dari kegiatan industri rumah tangga. Pewadahan yang digunakan tergolong wadah permanen dan semi permanen.

f. Tempat ibadah

Sumber sampah dihasilkan dari kegiatan keagamaan. Pewadahan yang digunakan tergolong wadah permanen dan semi permanen.

g. Warung dan toko

Sumber sampah dihasilkan dari kegiatan warung dan toko. Pewadahan yang digunakan tergolong wadah permanen dan semi permanen. 


\section{Densitas Sampah}

Pengambilan sampel densitas sampah dilakukan selama 8 hari berturut-turut menggunakan kotak densitas yang berukuran 500 L. Pengambilan sampel densitas sampah komposisi menggunakan kotak densitas berukuran 40 L. Sebelum diisi sampah, kotak densitas ditimbang terlebih dahulu untuk mengetahui berat kotak densitas tersebut. Kotak densitas yang berisi sampah dihentakkan ke tanah 3 kali, kemudian diukur penurunan sampah. Contoh perhitungan densitas sampah adalah sebagai berikut:

Volume bak (Vbak)

$=p \times 1 \times t$

$=1 \mathrm{~m} \times 0,5 \mathrm{~m} \times 0,85 \mathrm{~m}$

$=0,43 \mathrm{~m}^{3}$

Berat bak (Wbak $)=18 \mathrm{~kg}$

Wbak + Sampah $=89 \mathrm{~kg}$

Berat sampah $($ Wsampah $)=($ Wbak + Sampah) - Wbak

$=89 \mathrm{~kg}-18 \mathrm{~kg}$

$=71 \mathrm{~kg}$

Densitas sampah $(\rho)=$ Densitas sampah : Volume sampah

$$
=71 \mathrm{~kg}: 0,43 \mathrm{~m}^{3}
$$

$=167,06 \mathrm{~kg} / \mathrm{m}^{3}$

Tabel 1 menampilkan densitas sampah campuran.

Tabel 1. Densitas sampah campuran

\begin{tabular}{|c|c|}
\hline Hari & $\begin{array}{l}\text { Densitas } \\
\text { sampah }(\mathrm{kg} / \mathrm{m} 3)\end{array}$ \\
\hline Selasa & 167,06 \\
\hline Rabu & 146,81 \\
\hline Kamis & 177,78 \\
\hline Jumat & 142,22 \\
\hline Sabtu & 160,92 \\
\hline Minggu & 160,49 \\
\hline Senin & 166,67 \\
\hline Selasa & 175,00 \\
\hline Rata-rata & 162,12 \\
\hline
\end{tabular}

(Sumber : Data Primer, 2020)

Nilai densitas dipengaruhi oleh berat sampah dan volume sampah pada kotak densitas saat dilakukan pengukuran (Khoirunnisa dkk., 2018).

\section{Timbulan Sampah}

Pengukuran Timbulan sampah dilakukan selama 8 hari. Pengukuran timbulan sampah didapatkan dengan menghitung volume sampah dari alat pengangkut sampah yang masuk ke TPST dan dikalikan dengan hasil densitas sampah. Contoh perhitungan timbulan sampah pada TPST Sampurno pada hari ke-1:

Timbulan Sampah = volume sampah pada hari ke $1 \times$ densitas sampah hari ke 1

$$
\begin{aligned}
& =22,56 \mathrm{~m}^{3} / \mathrm{hari} \times 167,06 \mathrm{Kg} / \mathrm{m}^{3} \\
& =3768,85 \mathrm{Kg} / \mathrm{hari}
\end{aligned}
$$

Tabel 2 menampilkan data timbulan sampah di TPST Sampurno.

Tabel 2. Timbulan sampah

\begin{tabular}{|l|l|}
\hline Hari & $\begin{array}{c}\text { Timbulan } \\
\text { sampah (kg/hari) }\end{array}$ \\
\hline Selasa & 3768,85 \\
\hline Rabu & 3312,00 \\
\hline Kamis & 4010,67 \\
\hline Jumat & 2912,71 \\
\hline Sabtu & 3630,34 \\
\hline Minggu & 3620,74 \\
\hline Senin & 6480,00 \\
\hline Selasa & 3584,00 \\
\hline Rata-rata & 3914,91 \\
\hline
\end{tabular}

(Sumber : Data Primer, 2020)

Berdasarkan Tabel 2 diketahui bahwa total timbulan sampah di TPST Sampurno sebesar $31.319,31 \mathrm{Kg} / \mathrm{hari}$ dengan rata-rata timbulan sampah sebesar $3.914,91 \mathrm{Kg} / \mathrm{hari}$.

\section{Komposisi Sampah}

Komposisi sampah merupakan komponen-komponen sampah yang diolah setiap hari oleh TPST (Cahya \& Pandebesie, 2017). Komposisi sampah dapat digunakan untuk menentukan pengolahan sampah yang tepat (Windraswara \& Prihastuti, 2017). Pemilahan jenis-jenis komposisi sampah telah ditentukan melihat dari penelitian terdahulu (Ratya \& Herumurti, 2017). Perhitungan persentase komposisi sampah dihitung dari berat sampah per jenis dibagi berat total dan dikalikan 100. Adapun hasil dari komposisi sampah akan disajikan pada diagram dalam Gambar 1, dimana tampak bahwa komposisi sampah adalah logam $1 \%$, sampah kaca $1 \%$, sampah lain-lain $0 \%$. 


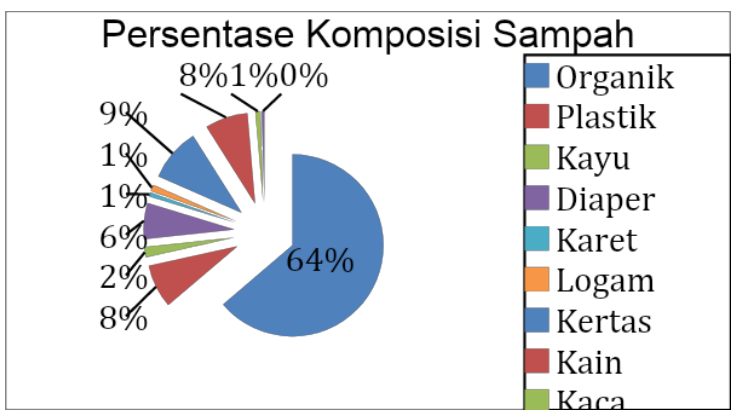

Gambar 1. Komposisi sampah

\section{Evaluasi Pengolahan Teknis Sampah di TPST Sampurno}

Evaluasi adalah sebuah kegiatan penilaian yang membandingkan suatu tempat dengan peraturan yang berlaku, bertujuan untuk mencapai hasil yang lebih baik (Hapsari, 2014). Hasil evaluasi pada TPST Sampurno ditampilkan pada Tabel 3. Berdasarkan Tabel 3, tidak ada satupun kriteria yang sesuai dengan Permen PU No. 03 Tahun 2013.

Tabel 3. Kelayakan TPST

\begin{tabular}{|c|c|c|c|c|}
\hline \multirow[t]{2}{*}{ No } & \multicolumn{2}{|c|}{ Komponen Kelayakan } & \multicolumn{2}{|c|}{ Kelayakan } \\
\hline & $\begin{array}{c}\text { PERMEN PU No. } \\
03 \text { thn } 2013\end{array}$ & Kondisi Eksisting & Layak & $\begin{array}{l}\text { Tidak } \\
\text { Layak }\end{array}$ \\
\hline 1. & $\begin{array}{l}\text { Luas TPST lebih } \\
\text { besar dari } 20.000 \\
\mathrm{~m}^{2}\end{array}$ & $\begin{array}{l}\text { Luas TPST } \\
\text { Sampurno sebesar } \\
1000 \mathrm{~m}^{2}\end{array}$ & & $\sqrt{ }$ \\
\hline 2. & $\begin{array}{l}\text { Jarak TPST ke } \\
\text { pemukiman } \\
\text { terdekat paling } \\
\text { sedikit } 500 \mathrm{~m}\end{array}$ & $\begin{array}{l}\text { Jarak TPST } \\
\text { Sampurno ke } \\
\text { pemukiman } \\
\text { terdekat sejauh } \\
\pm 200 \mathrm{~m} \\
\end{array}$ & & $\sqrt{ }$ \\
\hline 3. & $\begin{array}{l}\text { Produksi timbulan } \\
\text { sampah } 20-30 \\
\text { ton/hari }\end{array}$ & $\begin{array}{l}\text { Produksi timbulan } \\
\text { sampah di TPST } \\
\text { Sampurno sebesar } \\
\pm 8 \text { ton/hari }\end{array}$ & & $\sqrt{ }$ \\
\hline 4. & $\begin{array}{l}\text { Fasilitas TPST: } \\
\text { Ruang pemilah, } \\
\text { instalasi } \\
\text { pengolahan } \\
\text { sampah, } \\
\text { pengendalian } \\
\text { pencemaran } \\
\text { lingkungan, } \\
\text { penanganan } \\
\text { residu, dan } \\
\text { fasilitas penunjang } \\
\text { serta zona } \\
\text { penyangga }\end{array}$ & $\begin{array}{l}\text { Fasilitas di TPST } \\
\text { Sampurno : Tidak } \\
\text { ada pengolahan } \\
\text { sampah }\end{array}$ & & $\sqrt{ }$ \\
\hline
\end{tabular}

(Sumber : Data Primer, 2020)

\section{Redesain TPS3R Sampurno}

Berikut ini adalah redesain untuk TPS3R Sampurno:

1. Ruang penyortiran

Volume sampah $=56,79 \mathrm{~m}^{3} /$ hari

Kapasitas Gerobak $=5,12 \mathrm{~m} 3 /$ hari Jam kerja $=8$ jam/hari
Tinggi timbunan sampah $=0,7 \mathrm{~m}$

Luas $=\mathrm{V}$ sampah $: \mathrm{h}$ timbunan sampah $=56,79 \mathrm{~m}^{3} /$ hari $: 0,7 \mathrm{~m} /$ hari

$=81,12 \mathrm{~m}^{2}$

Jika panjang dan lebar dibuat sama, maka:

Panjang dan lebar $=\sqrt{81,12}$

$$
=9 \mathrm{~m}
$$

Kemudian ditambahkan $1 \mathrm{~m}$ untuk mempermudah proses mobilisasi pekerja dan penyortiran, sehingga lebar dan panjang menjadi $10 \mathrm{~m}$.

\section{Ruang pengemasan dan} penyimpanan barang lapak

Volume sampah terolah $=5,21 \mathrm{~m} 3$

Tinggi tumpukan rencana $=1 \mathrm{~m}$

Luas $=\mathrm{V}$ Sampah terolah $: \mathrm{h}$ tumpukan rencana

$=5,21 \mathrm{~m}^{3}: 1 \mathrm{~m}$

$=5,21 \mathrm{~m}^{2}$

Jika panjang dan lebar dibuat sama, maka:

Panjang dan lebar $=\sqrt{5,21}$

$$
=2,28 \mathrm{~m} \approx 2,5 \mathrm{~m}
$$

Kemudian ditambahkan $1 \mathrm{~m}$ untuk mempermudah proses mobilisasi pekerja dan pengemasan, sehingga lebar dan panjang menjadi $3,5 \mathrm{~m}$.

\section{Penampungan dan pencacahan sampah organik}

Volume sampah organik $=28,97 \mathrm{~m}^{3} /$ hari

Berat sampah organik $=4676,88 \mathrm{~kg} / \mathrm{hari}$

Jam kerja di TPS3R = 8 jam/hari

Tinggi maksimum timbunan sampah= $1,5 \mathrm{~m}$

$\checkmark$ sampah organik per jam:

V sampah $=$ V sampah : jam kerja

$$
=28,97 \mathrm{~m}^{3} / \text { hari }: 8 \mathrm{jam} / \text { hari }
$$$$
=3,62 \mathrm{~m}^{3} / \mathrm{jam}
$$

Luas $=\mathrm{V}$ sampah organik $: \mathrm{h}$ timbunan

$=28,97 \mathrm{~m}^{3} /$ hari $: 1,5 \mathrm{~m}$

$=19,31 \mathrm{~m}^{2}$

Jika panjang dan lebar dibuat sama, maka:

Panjang dan lebar $=\sqrt{19,31}$

$$
=4,39 \mathrm{~m} \approx 4,5 \mathrm{~m}
$$

Kemudian ditambahkan $1,5 \mathrm{~m}$ untuk alat pencacah dan mempermudah proses mobilisasi pekerja. Sehingga lebar dan panjang menjadi $6 \mathrm{~m}$.

\section{Ruang pengomposan sampah organik}

Berat sampah organik $=4676,88 \mathrm{~kg} / \mathrm{hari}$

Densitas $=137,54 \mathrm{~kg} / \mathrm{m}^{3}$

Volume sampah yang dikomposkan:

$\mathrm{V}=($ waktu $\mathrm{x}$ berat $):$ densitas 
$=(7$ hari $\times 4676,88 \mathrm{~kg} /$ hari $): 137,54 \mathrm{~kg} / \mathrm{m}^{3}$

$=238,02 \mathrm{~m}^{3}$

Kriteria desain open windrow:

Lebar bawah ventilasi $=0,6-0,9 \mathrm{~m}$

Tinggi timbunan $=1,75 \mathrm{~m}$

Lebar timbunan $=2,5 \mathrm{~m}-3,5 \mathrm{~m}$

Perhitungan volume windrow dan penentuan jumlah windrow:

Ukuran open aerator windrow: Panjang 5m; Lebar 0,6m; Tinggi 0,6m

Volume aerator Open Windrow:

$\mathrm{V}=(\mathrm{p} \times \mathrm{x} \mid \mathrm{x}): 2$

$=5 \mathrm{~m} \times 0,6 \mathrm{~m} \times 0,6 \mathrm{~m}$

$=1,8 \mathrm{~m}^{3}$

Ukuran timbunan kompos: Panjang $5 \mathrm{~m}$;

Lebar atas 2,5m; Lebar bawah 3,5 m; Tinggi

$1,75 \mathrm{~m}$

Luas area melintang (trapesium)

$\mathrm{L}=(\mathrm{a}+\mathrm{b}) \times(\mathrm{h}: 2)$

$=(2,5+3,5) \times(1,75: 2)$

$=5,2 \mathrm{~m}^{2}$

Volume setiap windrow:

Volume $=$ Luas area melintang $\left(\mathrm{m}^{2}\right) \times$ panjang windrow $(\mathrm{m})$

$=5,2 \mathrm{~m} 2 \times 5 \mathrm{~m}$

$=26 \mathrm{~m}^{3}$

Volume timbunan kompos tanpa aerator

$\mathrm{V}=\mathrm{V}$ setiap windrow $-\mathrm{V}$ aerator

$=26 m^{3}-1,8 m^{3}$

$=24,2 \mathrm{~m}^{3}$

Penentuan jumlah windrow:

Jumlah windrow $=$ Tot $\mathrm{V}$ pengomposan $: \mathrm{V}$

setiap windrow

$=238,02 \mathrm{~m}^{3}: 26 \mathrm{~m}^{3}$

$=9,15$ unit $\approx 10$ unit

Kemudian ditambahkan $1 \mathrm{~m}$ untuk mempermudah proses mobilisasi pekerja dan $20 \mathrm{~cm}$ untuk saluran air lindi.

5. Bak penampung lindi

W sampah dikomposkan: 4676,88 kg/hari

Kadar air dalam sampah: $55 \%$

Kadar air kompos $\quad: 45 \%$

Kandungan air dalam lindi: 4676,88/hari $\times$ (55\%-45\%)

Berat jenis lindi $=1300 \mathrm{~kg} / \mathrm{m}^{3}$

Volume lindi $=$ kandungan air lindi : berat jenis air lindi

$=467,7 \mathrm{~kg} / \mathrm{hari}: 1300 \mathrm{~kg} / \mathrm{m}^{3}$

$=0,36 \mathrm{~m}^{3} /$ hari

Direncanakan volume bak dalam 30 hari, sehingga:

Vol. bak penampung lindi $=30$ hari $\times \mathrm{V}$ lindi

$=30$ hari $\times 0,36 \mathrm{~m}^{3} /$ hari

$=10,8 \mathrm{~m}^{3}$ $\mathrm{h}$ bak lindi $=1,5 \mathrm{~m}$

Luas $=\mathrm{V}$ bak penampung $: \mathrm{h}$ bak lindi

$=10,8 \mathrm{~m}^{3}: 1,5 \mathrm{~m}$

$=7,2 \mathrm{~m}^{2}$

Jika panjang dan lebar dibuat sama, maka:

Panjang dan lebar $=\sqrt{7,2 \mathrm{~m} 2}$

$$
=2,68 \mathrm{~m} \approx 3 \mathrm{~m}
$$

Air dalam bak penampung lindi diresirkulasi untuk penyiraman kompos.

\section{Pengayakan dan penyimpanan kompos}

Volume sampah organik $=28,97 \mathrm{~m}^{3}$

Tinggi rencana tumpukan $=1 \mathrm{~m}$

Volume kompos per hari $=\frac{1}{3} \times$ kompos awal

$$
\begin{aligned}
& =\frac{1}{3} \times 28,97 \mathrm{~m}^{3} \\
& =9,65 \mathrm{~m}^{3} \\
\text { Volume kompos halus } & =9,65 \mathrm{~m}^{3} \times 70 \% \\
& =6,75 \mathrm{~m}^{3} \\
\text { Volume kompos kasar } & =9,65 \mathrm{~m}^{3} \times 30 \% \\
& =2,90 \mathrm{~m}^{3}
\end{aligned}
$$

Proses pengomposan sampah akan berkurang $60 \%$ (Budihardjo, 2006).

Berat Kompos $=60 \% \times 4676,88 \mathrm{~kg} / \mathrm{hari}$

$$
=2806,12 \mathrm{~kg} / \mathrm{hari}
$$

Berikut ini adalah perhitungan lahan pengayakan dan pengemasan kompos:

Luas lahan Kompos halus $=\mathrm{V}$ kompos halus

: h rencana tumpukan

$=6,75 \mathrm{~m}^{3}: 1 \mathrm{~m}$

$=6,75 \mathrm{~m}^{2}$

Jika panjang dan lebar dibuat sama, maka:

Panjang dan lebar $=\sqrt{6,75 \mathrm{~m} 2}$

$$
=2,6 \mathrm{~m}
$$

Luas lahan Kompos halus $=\mathrm{V}$ kompos kasar : h rencana tumpukan

$$
=2,90 \mathrm{~m}^{3}: 1 \mathrm{~m}
$$$$
=2,90 \mathrm{~m}^{2}
$$

Jika panjang dan lebar dibuat sama, maka:

Panjang dan lebar $=\sqrt{2,90 \mathrm{~m} 2}$

$$
=1,7 \mathrm{~m}
$$

Dengan ditambah mesin pengayak maka panjang $5,5 \mathrm{~m}$ dan lebar $3 \mathrm{~m}$.

\section{Penyimpanan kompos}

Berat kompos $=2806,12 \mathrm{~kg} / \mathrm{hari}$

Volume $=\frac{2806,12 \mathrm{~kg} / \text { hari }}{700 \mathrm{~kg}} \times 1 \mathrm{~m}^{3}$

$$
\begin{aligned}
& =4 \mathrm{~m}^{3} \\
\text { Luas } & =\frac{\text { Volume }}{\text { Tinggi tumpukan }} \\
& =\frac{4 \mathrm{~m}^{3}}{1 \mathrm{~m}} \\
& =4 \mathrm{~m}^{2}
\end{aligned}
$$

Jika panjang dan lebar dibuat sama, maka: 


$$
\begin{aligned}
& =\sqrt{\text { luas }} \\
& =\sqrt{4 m^{2}} \\
& =2 \mathrm{~m}
\end{aligned}
$$

Kemudian ditambahkan satu meter untuk mempermudah proses mobilisasi pekerja.

\section{Bak container}

Berat residu sampah $=3649,21 \mathrm{~kg} /$ hari

Kapasitas arm roll truck $=6 \mathrm{~m}^{3}$

Densitas sampah di kontainer $=200-400$ $\mathrm{kg} / \mathrm{m}^{3}$

Volume residu $=\mathrm{W}$ residu sampah: Densitas sampah container

$$
=3649,21 \mathrm{~kg} / \text { hari : } 350 \mathrm{~kg} / \mathrm{m}^{3}
$$

$$
=10,42 \mathrm{~m}^{3}
$$

Jadi, arm roll truck yang dibutuhkan sebanyak 2 kontainer dengan kapasitas $6 \mathrm{~m}^{3}$. Rekapan kebutuhan lahan ditampilkan pada Tabel 4.

Tabel 4. Kebutuhan lahan

\begin{tabular}{|c|l|c|c|c|}
\hline No & Kebutuhan Lahan & $\begin{array}{c}\text { Luas } \\
\text { Eksisting }\end{array}$ & $\begin{array}{c}\text { Luas } \\
\text { Perencanaan }\end{array}$ & $\begin{array}{c}\text { Selisih } \\
\text { Luas }\end{array}$ \\
\hline A. & Hanggar & 300 & 434,25 & 134,25 \\
\hline 1 & Area penyortiran & & 100 & \\
\hline 2 & $\begin{array}{l}\text { Arean pengemasan } \\
\text { barang lapak }\end{array}$ & & 12,25 & \\
\hline 3 & $\begin{array}{l}\text { Area Penampungan } \\
\text { dan Pencacahan } \\
\text { Sampah Organik }\end{array}$ & & 36 & \\
\hline 4 & $\begin{array}{l}\text { Area pengomposan } \\
\text { sampah organik }\end{array}$ & & 247,5 & \\
\hline 5 & $\begin{array}{l}\text { Bak penampung } \\
\text { lindi }\end{array}$ & & 9 & \\
\hline 6 & $\begin{array}{l}\text { Area Pengayakan } \\
\text { dan Pengemasan } \\
\text { Kompos }\end{array}$ & & 16,5 & \\
\hline 7 & $\begin{array}{l}\text { Area penyimpanan } \\
\text { kompos }\end{array}$ & & 9 & \\
\hline B. & $\begin{array}{l}\text { Komponen } \\
\text { penunjang }\end{array}$ & 9,25 & 77,25 & 68 \\
\hline 1 & Kantor & 7 & 7 & \\
\hline 2 & Toilet & 2,25 & 2,25 & \\
\hline 3 & Tempat parkir & & 36 & \\
\hline 4 & Musholla & & 12 & \\
\hline 5 & $\begin{array}{l}\text { Penyimpanan } \\
\text { peralatan }\end{array}$ & & 24 & \\
\hline
\end{tabular}

(Sumber : Data Primer, 2020)

\section{RAB (Rencana Anggaran Biaya)}

Biaya investasi adalah biaya yang diperlukan untuk membangun semua unit pengolahan. Perhitungan RAB berasal dari biaya untuk desain TPS3R. Perhitungan RAB ini menggunakan acuan HSPK Kabupaten Sidoarjo Tahun 2018. Tabel 5 menampilkan RAB untuk desain TPS3R.

Tabel 5. Rancangan Anggaran Biaya

\begin{tabular}{|l|l|l}
\hline No & Uraian Pekerjaan & Jumlah Harga \\
\hline
\end{tabular}

\begin{tabular}{|c|l|c|}
\hline & & \\
\hline 1 & Pekerjaan persiapan & $133.960 .530,74$ \\
\hline 2 & Pekerjaan tanah & $136.940 .625,60$ \\
\hline 3 & Pekerjaan lantai kerja & $1.647 .228,35$ \\
\hline 4 & Pekerjaan pondasi beton bertulang & $154.678 .565,64$ \\
\hline 5 & Pekerjaan kolom pondasi & $90.816 .686,93$ \\
\hline 6 & Pekerjaan lain lain & $28.301 .520,33$ \\
\hline 7 & Pekerjaan tanah & $120.107 .514,98$ \\
\hline 8 & Pekerjaan lantai & $306.611 .013,07$ \\
\hline 9 & Pekerjaan dinding & $309.009 .291,69$ \\
\hline 10 & Pekerjaan plumbing & $16.000 .000,00$ \\
\hline 11 & Pekerjaan dinding atap & $472.221 .876,03$ \\
\hline 12 & Pekerjaan atap & $144.279 .330,37$ \\
\hline 13 & Pengolahan sampah organik & $106.435 .000,00$ \\
\hline & Jumlah Total & $\mathbf{2 . 0 2 1 . 0 0 9 . 1 8 3 , 7 1}$ \\
\hline & Dibulatkan & $\mathbf{2 . 0 2 1 . 0 1 0 . 0 0 0 , 0 0}$ \\
\hline
\end{tabular}

(Sumber : Data Primer, 2020)

\section{KESIMPULAN}

Kondisi pengelolaan sampah eksisting di Kelurahan Kalisampurno adalah sampah diangkut dari sumber ke TPST, kemudian dipilah, dan diangkut TPA. Timbulan sampah TPST Sampurno rata-rata sebesar 3.914,91 $\mathrm{kg} /$ hari atau 24,14 $\mathrm{m}^{3}$. Densitas sampah rata-rata sebesar $162,12 \mathrm{~kg} / \mathrm{m}^{3}$ dan timbulan sampah per kapita rata-rata sebesar 0,41 $\mathrm{kg} / \mathrm{jiwa}$ /hari. Komposisi sampah didominasi oleh sampah organik $64 \%$ dan yang paling sedikit adalah lain-lain $0 \%$. Tidak ada satupun parameter yang sesuai dengan Permen $\mathrm{Pu}$ no.03 Tahun 2013. Hasil redesain TPST Sampurno sebesar $511,5 \mathrm{~m}^{2}$ dan direncanakan penambahan pengolahan sesuai dengan kebutuhan. RAB yang diperlukan untuk desain ulang sebesar Rp. 2.021.010.000,00.

\section{DAFTAR PUSTAKA}

Budihardjo, M.A., 2006, Studi Potensi Pengomposan Sampah Kota Sebagai Salah Satu Alternatif Pengelolaan Sampah di TPA dengan Menggunakan Aktivator EM4 (Effective Microorganism), Jurnal Presipitasi. Vol.1, No.1

Cahya, W.I. \& Pandebesie, E.S., 2017, Kajian Tempat Pengolahan Sampah Terpadu (TPST) Gunung Bahagia, Kota Balikpapan, Jurnal Teknik ITS, 6(2), 5.

Hapsari, N., 2014, Evaluasi Program Pengolahan Sampah Berskala Keluarga di Kelurahan Tembalang. Jurnal Teknik PWK. 3(1), 12.

Khoirunnisa, R., Ashari, M.L., \& Setiani, V., 2018, Pengukuran Timbulan, Densitas, Komposisi dan Kadar Air Limbah Padat Non B3 di PPNS, 2623, 6. 
Pratama, A.D., Priyambada, I.B., \& Handayani, D.S., 2017, Perencanaan Sistem Pengelolaan Sampah Terpadu, Jurnal Teknik Lingkungan. 6(1), 9.

Rahardjo, Slamet., \& Rima Geovani. (2015). Studi Timbulan, Komposisi, Karakteristik, dan Potensi Daur Ulang Sampah Non Domestik Kabupaten Tanah Datar, Jurnal Teknik Lingkungan UNAND, (1): 27-37

Ratya, H., \& Herumurti, W. (2017). Timbulan dan Komposisi Sampah Rumah Tangga di Kecamatan Rungkut Surabaya, Jurnal Teknik ITS, 6(2), hal. 2337-3520. https://doi.org/10.12962/j23373539.v6i2.2 4675.

Windraswara, R. \& Prihastuti, D.A.B., 2017, Analisis Potensi Reduksi Sampah Rumah Tangga untuk Peningkatan Kualitas Kesehatan Lingkungan, Unnes Journal of Public Health, 6(2), 123, https://doi.org/10.15294/ujph.v6i2.15360.

\section{BIODATA PENULIS}

Muhammad Naufal Rozan, lahir di Sidoarjo pada tanggal 5 Agustus 1996. Saat ini tercatat sebagai mahasiswa Teknik Lingkungan di Universitas Islam Negeri Sunan Ampel Surabaya.

Widya Nilandita, penulis menempuh pendidikan Sarjana dan Magister Jurusan Kesehatan Masyarakat di Universitas
Airlangga. Saat ini menjadi dosen tetap Program Studi Teknik Lingkungan Universitas Islam Negeri Sunan Ampel Surabaya

Arqowi Pribadi, penulis menempuh pendidikan sarjana Jurusan Teknik Sipil di Universitas Sebelas Maret Surakarta dan melanjutkan studi magister Jurusan Teknik Sipil di Universitas Gadjah Mada Yogyakarta. Saat ini menjadi dosen tetap Program Studi Teknik Lingkungan Universitas Islam Negeri Sunan Ampel Surabaya

Amrullah, penulis menempuh pendidikan Sarjana dan Magister Jurusan Pendidikan Agama Islam (PAI) di Universitas Islam Malang. Saat ini menjadi dosen tetap Program Studi Teknik Lingkungan Universitas Islam Negeri Sunan Ampel Surabaya

Shinfi Wazna Auvaria, penulis menempuh pendidikan Sarjana dan Magister Jurusan Teknik Lingkungan di Institut Teknologi Sepuluh Nopember. Saat ini menjadi dosen tetap Program Studi Teknik Lingkungan Universitas Islam Negeri Sunan Ampel Surabaya 